\title{
FERTILIZER ENCAPSULATION TO IMPROVE THE NUTRIENTS USE EFFICIENCY OF PLANT THROUGH SLOW/CONTROLLED RELEASE TO ENSURE FOOD SECURITY
}

\author{
Jayanudin $^{1,2, *}$ and R. S. D. Lestari ${ }^{1}$ \\ ${ }^{1}$ Chemical Engineering Department, Faculty of Engineering, Universitas Sultan Ageng Tirtayasa \\ Jl. Jenderal Sudirman km.3 Cilegon-Indonesia 42435 \\ ${ }^{2}$ Indonesian-Center of Excellence for Food Security, Universitas Sultan Ageng Tirtayasa \\ Jl. Raya Jakarta Km 4 Pakupatan, Serang-Indonesia 42118 \\ *E-mail : jayanudin@untirta.ac.id
}

\begin{abstract}
Global food security will be a major concern because it involves the availability of food that is not able to meet human needs. The decline in food production is caused by the low efficiency of fertilizer absorption by plants because it uses conventional fertilizers. One solution to increase crop productivity is to use slow-controlled release fertilizers. This technology can improve the nutrient use efficiency (NUE) and reduce the negative impact on the environment due to chemical fertilization and by inadequate disposal or reuse of agricultural waste. This study provides information about the design and use of slow-controlled release fertilizer that can control nutrient release and enhance NUE as a solution to food security problems.
\end{abstract}

Keywords: Composite Materials, Encapsulation Methods, Environmental Health, Microcapsule

(C) RASĀYAN. All rights reserved

\section{INTRODUCTION}

Food security throughout the world can be guaranteed by the addition of (inorganic) synthetic fertilizers which provide a crucial role by contributing nearly $50 \%$ of the increase in crop yield ${ }^{1}$. Global food security is highly dependent on three crops such as rice, wheat, and corn. The annual crop area of almost $58 \%$ is occupied by these three plants and can provide about $50 \%$ of food calories. Rice and wheat were energy suppliers for developing countries while corn has provided more than $60 \%$ of energy in animal feed $^{2,3}$. The addition of fertilizer aims to provide and balance nutrients in the soil. Increased human population causes food needs to increase. Food production can be increased by increasing fertilizer use.

The high consumption of fertilizers is not offset by its efficiency, conventional fertilizers have low nutrients use efficiency (NUE), the ability of plants to obtain nutrients, transport them in roots, and move other parts of plants. Nutrients use efficiency of major macronutrients such as nitrogen $(\mathrm{N})$, phosphorus $(\mathrm{P})$, and Potassium $(\mathrm{K})$ is very low, and the current level only reaches $30-35 \%, 18-20 \%$, and $35-40 \%{ }^{4}$. The remaining components which reach $60-80 \%$ of $\mathrm{N}, \mathrm{P}$, and $\mathrm{K}$ and excessive use of fertilizers can disrupt the balance of nutrients in the environment, causing many environmental problems including eutrophication of water bodies and disturbances in soil structure. The low nutrients use efficiency is caused by the high release of fertilizers rather than the absorption rate by plants. To enhance nutrient use efficiency, new types of smart fertilizers with the controlled nutrient release are needed Encapsulation of fertilizer has great potential in increasing the efficiency of fertilizer use and solving environmental problems caused by fertilizers.

Encapsulation is a process to protect active ingredients in the form of liquid, solid and gas from environmental influences. Active ingredients are protected or integrated within the matrix of the wall material such as polymers or biopolymers ${ }^{5,6}$. The function of the fertilizer encapsulation technique is the

Rasayan J. Chem., 13(2), 1074-1082(2020)

http://dx.doi.org/10.31788/RJC.2020.1325572

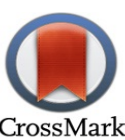


RASĀYAN J. Chem.

Vol. 13 | No. 2 |1074 - 1082| April - June | 2020

controlled release of fertilizer so that it can reduce environmental pollution due to excessive fertilizer release. Encapsulation methods are divided into chemical and mechanical techniques, such as simple coacervation, complex coacervation, molecular inclusion for chemical technique, spray-drying, spray chilling extrusion, and fluidized beds for mechanical technique ${ }^{7}$. Based on the above discussion, the goal of developing slow-controlled release fertilizers is to improve NUE and crop productivity.

\section{Food Security}

Food security defined by FAO is that every person, at any time, has physical, social and economic access to obtain adequate, safe and nutritious food, fulfill their food needs to maintain an active and healthy life. Food demand is expected to increase anywhere between $59 \%$ to $98 \%$ due to the growth of the population. The world population can reach 1.7 billion of the world's population by 2050 . Resources are limited and continue to shrink due to continued pressure by an increasing population. Resource efficiency needs to be done because the results of the investigation showed that $30-50 \%$ of food produced is never consumed and becomes waste ${ }^{8}$.

The problem of food security is very complex because it covers many fields that must be resolved. Figure 1 showed the pillars of inter-relationship food security, so it is very unlikely to solve only one root cause. McCarthy et $\mathrm{al}^{8}$ has described the four pillars of food security as follows:

\section{Food Availability}

The provisions of this pillar are to have a minimum quantity of available and adequate food. The consideration is to produce food locally or imported. Other considerations are food stocks that exist in a particular area and food assistance that has been determined and assigned from other countries. The important thing that should be noted is that the availability of high demand does not guarantee food security.

\section{Food Access}

Physical and/or economic access o food is considered in this pillar. The level of income (per population), purchasing power, infrastructure, and financial means to support trade within/across certain regions are the most important factors.

\section{Food Utilization}

Supply chain and food handling through a security perspective is the focus of this pillar. All primer production, secondary processing, distribution, retail and household must be hygiene. The creation of nutritional awareness among stakeholders from different foods is needed to create efficient and safe food use.

\section{Food Stability}

The focus of this pillar is stability from the perspective of supply and access. These factors are influenced by price, political stability, and the local economy. Another factor that must be considered is weather patterns that hurt crop yields.

In this review, the goal of developing slow-controlled release fertilizers is to improve NUE in plants and crop productivity. Yield crops can increase if the NUE fertilizer is high. Increasing yield crop directly affect food availability which is one of the food security pillars. Nutrients (fertilizers) of plants such as nitrogen, potassium, and phosphorus in conventional fertilizers are absorbed by plants only $18-40 \%$, Guo $\mathrm{et} \mathrm{al}^{4}$ the remainder settles in the soil and is carried by the flow of water. Excessive nutrients in the soil cause imbalances in the environment and cause environmental problems including disruption of soil structure and eutrophication of water bodies. Environmental problems indirectly can hurt handling food security.

The future challenge that must be resolved is the efficient use of nutrients (fertilizers) by plants to increase crop productivity. Several studies have made fertilizer modifications using materials that function to slow/controlled release of these fertilizers, such as organic polymer coatings (Thermo-plastics 
RASĀYAN J. Chem.

Vol. 13 | No. 2 |1074 - 1082| April - June | 2020

and resins) and inorganic coatings (sulfur and mineral-based) ${ }^{10}$. This fertilizer modification is expected to increase food availability to overcome food security.

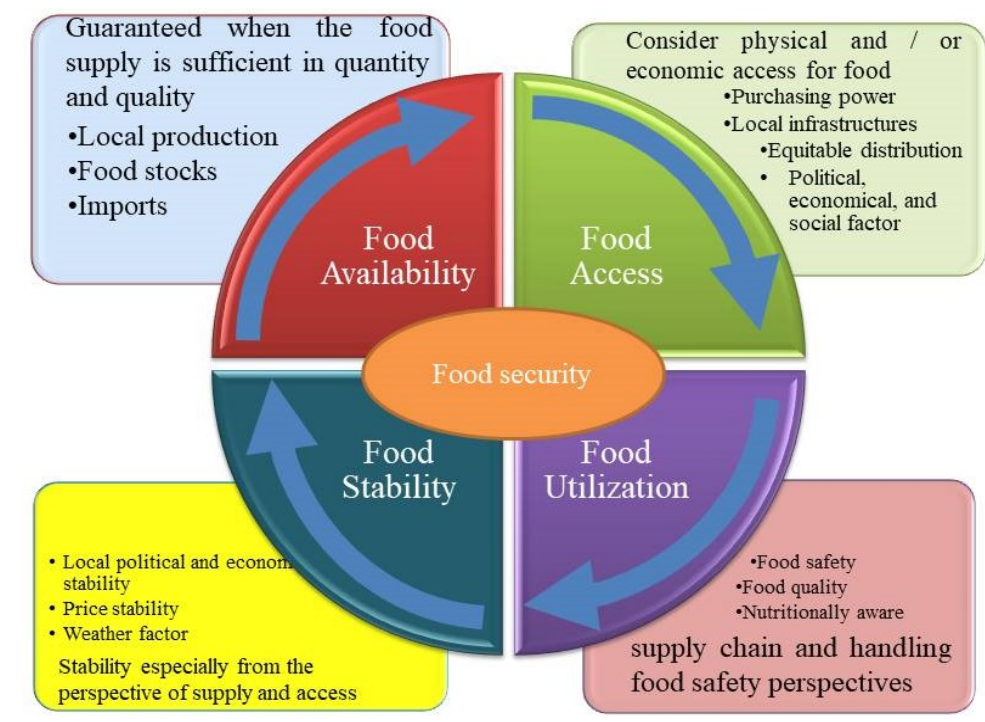

Fig.-1: Basic Concepts and Relationships between the Four Pillars of Food Security

[Source: McCarthy et $\mathrm{al}^{8}$; Cawthorn and Hoffman ${ }^{9}$ ]

\section{Nutrients Use Efficiency(NUE)}

Plant growth and development only require 16 essential elements, namely carbon and oxygen from $\mathrm{CO}_{2}$, and hydrogen from water $\left(\mathrm{H}_{2} \mathrm{O}\right)$. All three elements are needed in large quantities to produce constituents such as cellulose or starch. Other elements are 13 nutrients in the form of minerals (inorganic) which are divided into macronutrients and micronutrients ${ }^{11}$. About $95 \%$ of plant biomass is formed by oxygen, carbon, and hydrogen, while $5 \%$ is formed by other elements. $95 \%$ of plant biomass is formed by oxygen, carbon, and hydrogen, while $5 \%$ is formed by other elements. The difference in plant concentration between macronutrients and micronutrients is very large. For example, Nitrogen $(\mathrm{N})$ and molybdenum (Mo) in plants is a ratio of 10,000:1. While plants need 40 times greater magnesium $(\mathrm{Mg})$ than iron (Fe).he difference in plant concentration between macronutrients and micronutrients is very large. For example, Nitrogen $(\mathrm{N})$ and molybdenum $(\mathrm{Mo})$ in plants is a ratio of 10,000: 1. Another example is plants need 40 times greater magnesium $(\mathrm{Mg})$ than iron $(\mathrm{Fe}) .{ }^{11}$ Table-1 shows important plant nutrients and their typical concentration in plants.

Table-1: Essential nutrients of plant in their typical concentration ${ }^{11}$

\begin{tabular}{|c|c|c|}
\hline Nutrient & Form absorbed & Typical concentration in plant dry matter \\
\hline \multicolumn{3}{|l|}{ Macronutrients } \\
\hline Nitrogen $(\mathrm{N})$ & $\mathrm{NH}_{4}^{+}, \mathrm{NO}_{3}$ & $1.5 \%$ \\
\hline Potassium (K) & $\mathrm{K}^{+}$ & $1-5 \%$ \\
\hline Phosphorus (P) & $\mathrm{H}_{2} \mathrm{PO}_{4}^{-}, \mathrm{HPO}_{4}^{2-}$ & $0.2-0.4 \%$ \\
\hline Calcium $(\mathrm{Ca})$ & $\mathrm{Ca}^{2+}$ & $0.2-1.0 \%$ \\
\hline Sulphur (S) & $\mathrm{SO}_{4}{ }^{2-}$ & $0.1-0.4 \%$ \\
\hline Magnesium (Mg) & $\mathrm{Mg}^{2+}$ & $0.1-0.4 \%$ \\
\hline \multicolumn{3}{|l|}{ Micronutrients } \\
\hline Boron $(\mathrm{B})$ & $\mathrm{H}_{3} \mathrm{BO}_{3}, \mathrm{H}_{2} \mathrm{BO}_{3}$ & $6-60 \mu \mathrm{g} / \mathrm{g}(\mathrm{ppm})$ \\
\hline Iron $(\mathrm{Fe})$ & $\mathrm{Fe}^{2+}$ & $50-250 \mu \mathrm{g} / \mathrm{g}(\mathrm{ppm})$ \\
\hline Manganese (Mn) & $\mathrm{Mn}^{2+}$ & $20-500 \mu \mathrm{g} / \mathrm{g}(\mathrm{ppm})$ \\
\hline Copper $(\mathrm{Cu})$ & $\mathrm{Cu}^{+}, \mathrm{Cu}^{2+}$ & $5-20 \mu \mathrm{g} / \mathrm{g}(\mathrm{ppm})$ \\
\hline Zinc (Zn) & $\mathrm{Zn}^{2+}$ & $21-150 \mu \mathrm{g} / \mathrm{g}(\mathrm{ppm})$ \\
\hline Molybdenum (Mo) & $\mathrm{MoO}_{4}{ }^{2-}$ & below $1 \mu \mathrm{g} / \mathrm{g}(\mathrm{ppm})$ \\
\hline Chlorine $(\mathrm{Cl})$ & $\mathrm{Cl}^{-}$ & $0.2-2 \%$ \\
\hline
\end{tabular}


RASĀYAN J. Chem.

Vol. 13 | No. 2 |1074 - 1082| April - June | 2020

Fertilizers that contain nutrient minerals, when applied to the soil, they are scattered by water molecules and split into the forms needed by plants. Conventional fertilizers have deficiencies because some nutrients are lost through leaching and increasingly contaminate underground water aquifers ${ }^{12}$. These problems cause the efficiency of the absorption of nutrients by plants to be low.

NUE is a concept used to evaluate crop production systems and is influenced by fertilizer management and soil and plant-water relationships. NUE indicates the potential loss of nutrients to the environment from the planting system because it seeks to meet people's demands for increasing food ${ }^{13}$. Higher NUE by plants can reduce fertilizer input costs, reduce nutrient losses, and increase crop yields. Factors that influence NUE are plant genetic, morphological, physiological plant and their interactions with external factors such as soil temperature and humidity, light, soil biological, and fertilizer materials. NUE is evaluated based on differences in plant species, genotypes, and cultivars. This is due to its ability to absorb and utilize nutrients to the fullest. There are 3 bases of NUE, such as uptake efficiency, incorporation efficiency, and utilization efficiency. ${ }^{14}$

Fertilizer is one of the main factors used to enhance crop yield. Excessive use of fertilizers and pesticides has led to the problem of air, water, and soil pollution. The effort used to overcome this problem is to make a slow/controlled-release fertilizer by encapsulation to prevent the loss of chemicals during irrigation and reduce degradation by microbial decomposition, photolysis, and hydrolysis ${ }^{15}$.

\section{Encapsulation of Fertilizer}

Encapsulation is a process of coating core materials (liquid, solid, and gas) using thin wall materials or embedded in homogeneous or heterogeneous matrices to form small capsules ${ }^{16}$. Encapsulation is used to protect active ingredients that are sensitive to environmental influences. Another function is to control the release of a core material with a certain concentration and time so that it can improve the efficiency of nutrient use. The wall material used for encapsulation is usually from polymers/biopolymers (carbohydrates and proteins).

Figure-2 showed the form of microcapsules adopted from Dubey et $\mathrm{al}^{5}$, Jayanudin et $\mathrm{al}^{6}$, and Bakry et $\mathrm{al}^{16}$. The shape and size of microcapsules depend on the wall material and the method used. According to Dubey et $\mathrm{al}^{5}$ and Mishra ${ }^{17}$ microcapsules can be categorized into several classifications, such as:

1. Single-core: Microcapsules that have a single core with single shell material.

2. Multicore: These microcapsules have many different size hollow chambers within the capsule.

3. Matrix: Matrix-type microcapsule has active ingredients embedded in the matrix of the wall material.

Besides three categories, there is also a single core with a multiwall or multicore with multiwall microcapsule.

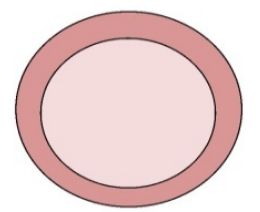

A

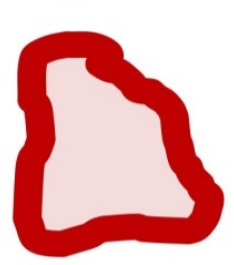

$\mathrm{F}$

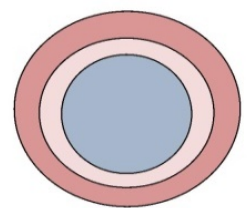

$\mathrm{B}$

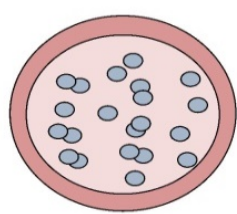

$\mathrm{E}$

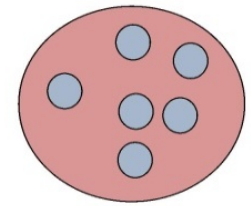

$\mathrm{C}$

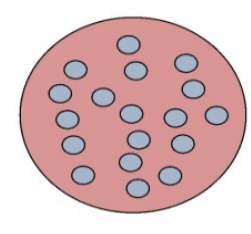

$\mathrm{D}$

Fig.-2: Differences in Types of Microcapsules: A. Monocore (Reservoir), B. Multiwall Microcapsule, D. Matrix (Microsphere), E. Multiwall Microsphere, and E. Irregular Microcapsule 
RASĀYAN J. Chem.

Vol. 13 | No. 2 |1074 - 1082| April - June | 2020

\section{Advantages and Disadvantages of Slow/ Controlled Release Fertilizer}

The use of controlled-release fertilizers is advantageous compared to conventional fertilizers. The following are the advantages and disadvantages of controlled-release fertilizers that summarized from Trenkel ${ }^{18}$.

\section{Advantages}

1. Slow-Controlled release fertilizer can reduce toxicity, especially for seedlings because the use of conventional fertilizers has a high ion concentration which induces osmotic stress and causes damage at different growth stage

2. Slow-Controlled release fertilizers can be used for multiple cropping with making a single application of fertilizer, because of reduced toxicity and salt content of the substrate.

3. The use of controlled-release fertilizers can save labor, time and energy. These factors can provide the greatest benefits for the consumer's majority.

4. Predictions of controlled release increase the uptake of nutrients by plants and significantly reduce the loss of nutrients, especially nitrate- $\mathrm{N}$ which disappears due to the volatility of ammonia and substantially reduces the risk of environmental pollution.

5. Polymer-coated fertilizers are less sensitive to soil and climatic conditions, so it can be a good prediction of nutrient release are possible with controlled-release fertilizers coated with hydrophobic materials.

\section{Disadvantages}

1. Fertilizer release patterns do not have a standard method because of the lack of correlation between laboratory testing data and the actual function of nutrient release patterns in field conditions. This is because there are no reports on the comparison of the advantages of controlled release and conventional fertilizers.

2. The released nutrients are expected to be only three-quarters of nutrition but in fact, almost $80 \%$ are released because of ignores the burst effect during the growth process. Controlled release fertilizer can be release nutrients too slow if coated thicker.

3. Sulfur-coated fertilizers with rapid initial nutrient release without causing damage to developing plants have a higher cost than conventional soluble fertilizers

4. Application of coated fertilizers (especially sulfur-coated urea) contribute to increasing soil acidity because it increases the uptake of phosphorus and iron

\section{Fertilizer Encapsulation Methods}

Fertilizer encapsulation methods are very diverse, from simple methods to complex methods. In this article only summarizes methods that are considered simple enough to be applied in fertilizer encapsulation. The method described in this article is divided into two, in which encapsulated fertilizers are using polymer materials and polymers composted with other materials.

\section{Encapsulation of Fertilizers using Polymers as Wall Material}

Polymers used as wall materials from the encapsulation of fertilizers have been reported, such as spraying, in situ polymerization, and mixing. In-situ polymerization methods are similar to interfacial polymerization. The difference is that no reactants included in the core material. Polymerization does not occur on both sides of the continuous phase interface and core material but all occur in a continuous phase. In-situ polymerization for encapsulation of fertilizer was reported by Rochmadi et $\mathrm{al}^{19}$ In-situ polymerization of urea-formaldehyde under low $\mathrm{pH}$ (acidic conditions) is the method applied. There are 2 steps that must be done. The first is the formation of palm oil emulsion in a solution of urea-formaldehyde resin with palm oil as a dispersed phase. The homogenizer is used as a high-speed stirrer to emulsify palm oil. The second step is the formation of the microcapsule wall (shell). In this stage, the $\mathrm{pH}$ is adjusted into acidic conditions. This was done to promote the reaction of urea with formaldehyde in the droplet emulsion interface to produce a film of the ureaformaldehyde polymer as a wall (shell) material for microcapsules. 
RASĀYAN J. Chem.

Vol. 13 | No. 2 |1074 - 1082| April - June | 2020

The encapsulation method with spraying is the most common method applied for fertilizer coating. The polymer solution in the appropriate solvent is sprayed on the fertilizer granules and then dried to remove the solvent. The percentage of coating is adjusted by repeating the spray treatment. Tomaszewska and Jarosiewicz ${ }^{20}$ have applied to spray methods to encapsulate mineral fertilizers. Their research used two stages: mineral fertilizer coated with a solution of polysulfone in N, Ndimethylformamide with a wet method. This method, mineral fertilizer granules are placed in the film-forming a layer. Furthermore, thin-coated granules of polymer solution are dropped in the precipitation bath and produce a form of a coating. The properties of the coated porous mineral layer can be improved by spraying using a polymer solution or pure solvent ( $\mathrm{N}, \mathrm{N}$-dimethylformamide). The concentration of polysulfone in the sprayed solution ranges from 15 to $17 \%$ by weight. Mineral fertilizers are placed in movable sieves and sprayed with solvents or adequate polymer solutions. Then granule fertilizer is dried in warm airflow.

The encapsulation method with mixing techniques has been reported by Abedi-Koupai et $\mathrm{al}^{21}$. Fertilizer (Compritol 888 ATO) is mixed with ethyl acetate, glycerol monostearate. After that, they are mixed with avicel and lactose. All components are mixed in the extruder. The microcapsules formed were dipped in an ethylene-vinyl acetate solution and then dried at room temperature.

\section{Encapsulation of Fertilizers using a Composite Technique}

Fertilizer encapsulation with composite techniques has the same purpose, namely to increase the efficiency of nutrient use and reduce the level of environmental pollution. Composite techniques aim to increase physical strength and holding a capacity of nutrients. Fertilizer encapsulation using wall material from polymers sometimes has poor physical strength, might be not suitable for water and contains salt. The nutrients contained in microcapsule can be quickly released with high permeability. Polymer composites aim to further enhance the strength of microcapsule walls to improve the efficiency of nutrient release. Composite techniques for encapsulation of fertilizers have been widely reported by researchers, this article only summarizes some of the results of studies relating to fertilizer encapsulation using composite techniques.

Microcapsule walls made with nanoclay-polymer composites have been reported by Sarkar et $\mathrm{al}^{22}$, combining nanoclay into superabsorbent polymers can reduce the diffusion coefficient of urea release from urea-loaded composite hydrogels. The nanoclay-polymer composite method begins with the preparation of Nanoclay-Polymer Composites (NCPCs). The solution of Acrylic acid and acrylamide is stirred using a magnetic stirrer then clay is added and dispersed in a monomer solution which is partially neutralized. The crosslinker, $\mathrm{N}, \mathrm{N}^{\prime}$-methylene bisacrylamide is added to the mixed solution and stirred slowly. After that ammonium persulfate was added as a radical initiator so that a polymerization reaction occurred. After completion, the product is washed with distilled water and dried, milled and screened. The loading of fertilizer (DAP and urea) was carried out by immersion dry gel into the solution of each fertilizer for 20 hours to achieve swelling equilibrium. After that, the products were dried, milled and screened.

NPK fertilizer encapsulated by carboxymethyl cellulose-based nanocomposite has been reported by Olad et $\mathrm{al}^{15}$, fertilizers are dispersed in Sulfonated carboxymethyl cellulose (SCMC) solution mixed with polyvinylpyrrolidone (PVP) and silica nanoparticles then stirred. A few minutes later Acrylic acid and N-N'-methylene bisacrylamide (MBA) as crosslinkers were added to the mixture. After removing dissolved oxygen with nitrogen, ammonium persulfate (APS) is added as the initiator agent, and then the temperature is raised to $60^{\circ} \mathrm{C}$ and stored in this condition for 4 hours for the polymerization process. The gel-like product was cut into small pieces and immersed in ethanol for 24 hours to remove impurities. The last step is the product is dried at $70^{\circ} \mathrm{C}$ in the oven for 24 hours.

Table- 2 shows several studies that have reportedly used composite materials to form controlled-release fertilizers.

Technology Slow/Controlled Release Fertilizer to Ensure Food Security and Environmental Health Conventional fertilizers such as urea and NPK have problems with the efficiency of nutrient absorption by plants and environmental damage caused by the amount of fertilizer that is not uptake by crops. Also, 
RASĀYAN J. Chem.

Vol. 13 | No. 2 |1074 - 1082| April - June | 2020

agricultural activities currently contribute to the annual atmospheric emissions of GHG (greenhouse gas) around $20 \%$, such as methane and carbon dioxide. The contribution of $\mathrm{N}_{2} \mathrm{O}$ is higher (about $60 \%$ ), which is GHG and a strong catalyst for stratospheric ozone depletion that is 300 times the global warming potential than $\mathrm{CO}_{2}$. These emissions are related to mineral fertilizer inputs. In this case, if it is mismanaged by intensive tillage and fertilization, soil can lose organic matter and become a source of $\mathrm{CO}_{2}{ }^{31}$.

Table-2: Microcapsule Wall Material From Composite Material

\begin{tabular}{|c|c|c|}
\hline Wall Material of Fertilizer Microcapsule & Type of Fertilizer & Reference \\
\hline Kaolinite Nanocomposite & Urea & 23 \\
\hline Kaolinite with chitosan binder & Urea & 24 \\
\hline Nanoclay/Superabsorbent Polymer Composites & Nitrogen and Phosphorus & 22 \\
\hline Nanoclay-polymer composites & Nitrogen & 22 \\
\hline Carboxymethyl cellulose-based nanocomposite & NPK & 15 \\
\hline Biochar-based waterborne copolymers & Urea & 1 \\
\hline Graphene oxide films & $\mathrm{KNO}_{3}$ pellets & 25 \\
\hline Bentonite and alginate composite & Microbial fertilizer & 26 \\
\hline $\begin{array}{c}\text { NaAlg-g-poly(AA-co-AAm)/MMT superabsorbent } \\
\text { nanocomposite }\end{array}$ & NPK & 27 \\
\hline $\begin{array}{c}\text { Cellulose-graft-poly(acrylamide)/nano- } \\
\text { hydroxyapatite/soluble fertilizer composite }\end{array}$ & NPK & 28 \\
\hline Zeolite based nano-composite & Micro-nutrients (Fertilizer) & 29 \\
\hline Hydroxyapatite nanoparticles & Urea & 30 \\
\hline
\end{tabular}

The effect of using conventional fertilizers is to harm the environment and increase the cost of using fertilizers because conventional fertilizers dissolve faster in water and the efficiency of absorption by plants is low. The solution is to increase the production and use of a smart fertilizer (slow-controlled release). Technological developments continue to increase but the use of slow-controlled release fertilizers is still low. The main reason is the limited use and high costs compared to conventional fertilizers. However, the reduced period of adding fertilizer can reduce the cost of purchasing fertilizers. The advantage of slow-controlled release fertilizer is to increase the absorption of nutrients by plants, improve the efficiency of fertilizer use during the growing season, extend the cycle of fertilizers, and reduce the risk of environmental pollution. Based on economic aspects and the environment, the use of slow-controlled release fertilizers can benefit farmers. Several researchers have produced and reported numerous slow-controlled release fertilizers with various modifications. In the future, the technology of slow-controlled release fertilizer can be applied to be able to further increase food production and reduce waste potential and become one of the solutions to food security.

\section{CONCLUSION}

Food security is an important issue that continues to be feared by both poor and developed countries. Various aspects of the field continue to find solutions to overcome food security until four pillars of food security are formed. These four pillars involve various aspects, ranging from increasing crop production until political aspects to solving problems of food security. One aspect that is expected to be a solution to increase crop productivity is to use slow-controlled release fertilizers. Conventional fertilizers that have low nutrient use efficiency (NUE) cause a decrease in the harvest and another effect is polluting the environment. Few studies report that the use of slow-controlled release fertilizers can increase NUE, soil productivity, lower nutrient loss, and reduce environmental pollution compared to conventional fertilizers. Future research should continue to explore and evaluate the composition of slow-release fertilizers, manufacture, and analysis of negative impacts on the environment. We also recommend using natural material to create slow-controlled release fertilizers to ensure the intensification of sustainability in agriculture.

\section{ACKNOWLEDGMENT}

The authors are grateful for the funding provided by IsDB through the Research Grant 4 in 1 IsDB Project through the scheme of Penelitian Dasar Unggulan IPTEK (PDUI). We also thank Chemical Engineering 
RASĀYAN J. Chem.

Vol. 13 | No. 2 |1074 - 1082| April - June | 2020

Department, Universitas Sultan Ageng Tirtayasa (UNTIRTA) for all research facilities that have been provided.

\section{REFERENCES}

1. S. Chen, M. Yang, C. Ba, S. Yu, Y. Jiang, H. Zou, Y. Zhang, Science of the Total Environment, 615, 431 (2018), DOI: 10.1016/j.scitotenv.2017.09.209

2. W.M. Stewart and T.L. Roberts, Procedia Engineering, 46, 76(2012), DOI: 10.1016/j.proeng.2012.09.448

3. R.A. Fischer, D. Byerlee, and G.O. Edmeades. Food and Agriculture Organization of the United Nations. Expert Meeting on "How to Feed the World in 2050", 24-26 June 2009, Rome.

4. M. Guo, M. Liu, R. Liang, A. Niu, Journal of Applied Polymer Science, 99(6), 3230(2006), DOI:10.1002/app.22892

5. R. Dubey, T.C. Shami, K.U.B. Rao, Defence Science Journal, 59(1), 82(2009), DOI: $10.14429 /$ dsj. 59.1489

6. Jayanudin, Rochmadi, M. Fahrurrozi, S.K. Wirawan, Journal of Applied Pharmaceutical Science, 6(12), 209(2016), DOI:10.7324/JAPS.2016.601232

7. A. Madene, M. Jacquot, J. Scher, S. Desobry, International Journal of Food Science and Technology, 41(1), 1(2006), DOI: 10.1111/j.1365-2621.2005.00980.x

8. U. McCarthy, I Uysal, R Badia-Melis, S. Mercier, C. O'Donnell, A. Ktenioudaki, Trends in Food Science and Technology, 77, 11(2018), DOI:10.1016/j.tifs.2018.05.002

9. D.M. Cawthorn and L.C. Hoffman, Food Research International, 76, 906(2015), DOI: 10.1016/j.foodres.2015.03.025

10. B. Azeem, Kushaari K, and Man ZB, A. Basit, T.H. Thanh, Journal of Controlled Release, 181(1), 11 (2014), DOI:10.1016/j.jconrel.2014.02.020

11. R.N. Roy, A. Finck, G.J. Blair, H.L.S. Tandon, Plant nutrients and basics of plant nutrition, in Plant Nutrition for Nutrient and Food Security, Food and Agriculture Organization of United Nation, Rome, pp. 25, (2006)

12. E. Elemike, I. Uzoh, D. Onwudiwe, O. Babalola, Applied Sciences, 9(3), 1(2019), DOI: 10.3390/app9030499

13. P Fixen, F Brentrup, T Bruulsema, F. Garcia, R. Norton, S. Zingore, 2015, Chapter 2. Nutrient/Fertilizer Use Efficiency: Measurement, Current Situation and Trends, in: D. Pay, P.Heffer, H.Magen, R. Mikkelsen, D.Wichelns (Eds.), Managing water and fertilizer for sustainable agricultural intensification, International Fertilizer Industry Association (IFA), International Water Management Institute (IWMI), International Plant Nutrition Institute (IPNI), and International Potash Institute (IPI), pp. 8-38, DOI:10.2136/sssaj2014.08.0328

14. V.C. Baligar, N.K. Fageria, and Z.L. He, Communications in Soil Science and Plant Analysis, 32(78), 921 (2002), DOI:10.1081/CSS-120003870

15. A. Olad, H. Zebhi, D. Salari, A. Mirmohseni, A. Reyhani Tabar, Materials Science and Engineering C. 90, 333 (2018), DOI:10.1016/j.msec.2018.04.083

16. A.M. Bakry, S. Abbas, B. Ali, H. Majeed, M.Y. Abouelwafa, A. Mousa, Comprehensive Reviews in Food Science and Food Safety, 15(1), 143(2016), DOI:10.1111/1541-4337.12179

17. M. Mishra, Handbook of Encapsulation and Controlled Release, CRC Press, Boca Raton, pp. 1-1481, (2015)

18. M. Trenkel, Advantages and disadvantages of slow- and controlled-release fertilizers and nitrification and urease inhibitors, In Slow-and controlled release and stabilized fertilizers, International Fertilizer Industry Association (IFA) Paris, France, p. 61-69, (2010)

19. Rochmadi, A. Prasetya, and W. Hasokowati, American Journal of Applied Sciences, 7(6), 739 (2010), DOI: 10.3844/ajassp.2010.739.745

20. M. Tomaszewska and A. Jarosiewicz, Desalination, 198(1-3), 346(2006), DOI:10.1016/j.desal.2006.01.032

21. J. Abedi-Koupai, J Varshosaz, M Mesforoosh, A.H. Khoshgoftarmanesh, Journal of Plant Nutrition, 35(8), 1130(2012), DOI:10.1080/01904167.2012.676126 
RASĀYAN J. Chem.

Vol. 13 | No. 2 |1074 - 1082| April - June | 2020

22. S. Sarkar, S.C. Datta, and D.R. Biswas, Journal of Applied Polymer Science, 131(6), 1(2014), DOI:10.1002/app.39951

23. S.I. Sempeho, H.T. Kim, E. Mubofu, A. Hilonga, Advances in Chemistry, 2014, 1(2014), DOI: $10.1155 / 2014 / 363071$

24. B. Roshanravan, S.M. Soltani, S.A. Rashid, F. Mahdavi, M.K. Yusop, Chemical Speciation and Bioavailability, 27(1), 44(2015), DOI:10.1080/09542299.2015.1023090

25. M. Zhang, B Gao, and J Chen, Y. Li, A.E. Creamer, H. Chen, Chemical Engineering Journal, 255, 107 (2014), DOI: 10.1016/j.cej.2014.06.023

26. Y. He, Z. Wu, L. Tu, Y. Han, G. Zhang, C. Li, Applied Clay Science, 109-110, 68 (2015), DOI: 10.1016/j.clay.2015.02.001

27. A. Rashidzadeh and A. Olad, Carbohydrate Polymers. 114, 269(2014), DOI:10.1016/j.carbpol.2014.08.010

28. K. Rop, G.N. Karuku, D. Mbui, I. Michira, N. Njomo, Annals of Agricultural Sciences, 63(2), 163 (2018), DOI: 10.1016/j.aoas.2018.11.001

29. A. Lateef, R. Nazir, N. Jamil S. Alam, R. Shah, M.N. Khan, M. Saleem, Microporous and Mesoporous Materials, 232, 174(2016), DOI:10.1016/j.micromeso.2016.06.020

30. N. Kottegoda, C. Sandaruwan, G. Priyadarshana, A. Siriwardhana, U. A. Rathnayake, D.M. B. Arachchige, A.R. Kumarasinghe, D. Dahanayake, V.Karunaratne, G. A. J. Amaratunga, ACS Nano, 11(2), 2017, DOI:10.1021/acsnano.6b07781

31. M. Calabi-Floody, J. Medina, C. Rumpel, L.M. Condron, M. Hernandez, M. Dumont, M. de la Luz Mora, Advances in Agronomy, 147, 119(2018), DOI:10.1016/bs.agron.2017.10.003

[RJC-5572/2020] 